Таким образом, Центральный Банк Российской Федерации обладает системой инструментов, которая позволяет влиять на процессы консолидации организаций в банковском секторе. Хотя официально Банк России не ставит целью ускорять или, наоборот, сдерживать процессы консолидации, тем не менее, он в состоянии активно воздействовать на данные процессы.

\title{
Литература
}

1. Петрущенков Ю.М. Сделки слияния/поглощения как стратегический инструмент управления стоимостью банковского бизнеса //Электронный ресурс. Режим доступа http://cyberleninka.ru/article/n/sdelki-sliyaniya-pogloscheniya-kak-strategicheskiy-instrumentupravleniya-stoimostyu-bankovskogo-biznesa (дата обращения 20.06.2019).

2. Степанов П.А. Процессы банковских слияний и поглощений: этапы развития и современные тенденции // Молодой ученый. 2014. № 19. С. 369 - 371.

Koyka Kristian Anatolyevich, postgraduate student of the Finance and credit Department, Economic Faculty, Peoples' Friendship University of Russia (6, Miklukho-Maklaya St., Moscow, 117198, Russian Federation).

E-mail: kris_fcsm_97@mail.ru

\section{THE ROLE OF THE BANK OF RUSSIA IN THE REGULATION OF PROCESSES OF CONSOLIDATION IN THE BANKING SECTOR OF RUSSIA \\ Abstract}

The article systematizes the tools that allow the Central Bank of the Russian Federation to influence the consolidation processes in the banking sector and assess their impact, considered the main mandatory standards for commercial banks, the dynamics of revocation and cancellation of licenses of credit organizations, and propose a formula for correctly calculating the ratio of the number of liquidations of credit organizations with the number of existing credit organizations in 2009-2018.

Keywords: banking sector, capital adequacy, consolidation, stability of a banking system, national economy, national banking system, bank technologies, Central Bank, capital of bank.

\section{References}

1. Petrushchenkov YU.M. Sdelki sliyaniya/pogloshcheniya kak strategicheskij instrument upravleniya stoimost'yu bankovskogo biznesa //Elektronnyj resurs. Rezhim dostupa http://cyberleninka.ru/article/n/sdelki-sliyaniyapogloscheniya-kak-strategicheskiy-instrument-upravleniya-stoimostyu-bankovskogo-biznesa (data obrashcheniya 20.06.2019).

2. Stepanov P.A. Processy bankovskih sliyanij i pogloshchenij: etapy razvitiya i sovremennye tendencii // Molodoj uchenyj. 2014. № 19. P. 369 - 371.

удк 325

DOI: $10.22394 / 2079-1690-2019-1-3-288-292$

\section{БЕЖЕНЦЫ ЧАКМА: ПРОБЛЕМЫ И ПЕРСПЕКТИВЫ УРЕГУЛИРОВАНИЯ}

\author{
Концова \\ Елизавета \\ Андреевна \\ аспирант, Санкт-Петербургский государственный университет \\ (199034, Россия, г. Санкт-Петербург, Университетская наб., 7-9). \\ E-mail: elizabethkontsova@gmail.com
}

\section{Аннотация}

Решение проблем беженцев является одним из факторов для достижения безопасности и устойчивого развития, поэтому важно привлечь внимание мирового сообщества к данному вопросу. Так, в статье рассматриваются проблемы беженцев чакма и перспективы их урегулирования. В первой части затрагивается историческая составляющая. Вторая часть посвящена основным причинам массовой миграции народа чакма. Третья часть статьи изучает попытки и указывает на актуальные проблемы урегулирования проблемы беженцев чакма.

Ключевые слова: Чакма, беженеи, вынужденная миграция, Южная Азия, региональная безопасность, Конвенция о статусе беженцев, политические последствия, племенные народы, политическая автономия.

\section{Введение}

Массовые вынужденные миграции являются одной из самых острых проблем, требующих поиска решений со стороны мирового сообщества. Число беженцев увеличивается с каждым годом [1], что обуславливает необходимость выработки современных универсальных механизмов урегулирования в рамках международного сотрудничества[2]. Вопросы размещения и депортации мигрантов прочно закрепились в обсуждениях на международных форумах и даже в предвыборных программах политиков.

Принятая в 1951 г. Конвенция о статусе беженцев заложила основы существующего ныне режима беженцев. Согласно принятому в Конвенции определению, «беженцем является лицо, которое 
... стало жертвой преследований по признаку расы, вероисповедания, гражданства, принадлежности к определенной социальной группе или политических убеждений, находится вне страны своей гражданской принадлежности и не может пользоваться защитой этой страны ... » [3].

Одним из наиболее проблемных с точки зрения количества беженцев является регион Южной Азии. Тысячи афганских, шриланкийских, тибетских, мьянманских беженцев становятся масштабной угрозой для региональной стабильности. Афганистан стал вторым после Сирии лидером по количеству генерируемых беженцев [4]. Согласно последнему докладу УВКБ ООН от 2017 года, южноазиатский регион занимает третье место по общему количеству беженцев после Африки и Ближнего Востока [5]. Потоки беженцев в Южной Азии имеют целый комплекс последствий политического и социально-экономического характера, что, безусловно, влияет на без того хрупкую стабильность региона, для которого характерны многочисленные конфликты, такие как война в Афганистане, Индо-Пакистанский конфликт и т.д.

Последствия раздела Индии отразились на судьбах многих народов субконтинента, став причиной беженства бенгальцев, рохинджа, бихари. Однако, одним из наиболее показательных примеров пагубного влияния процесса деколонизации стала трагичная судьба народа Чакма, изгнанного со своей родины и вынужденного искать себе новый дом.

\section{История народа чакма}

Чакма - один из древнейших племенных народов, проживающих в Читтагонгском горном районе, расположенном на северо-востоке современного государства Бангладеш. Чакма принадлежат к монголоидной расе, говорят на своем языке, относящемся к тибето-бирманской группе, имеют свою богатую культуру, традиции и обычаи.

В Читтагонгском горном районе проживало множество племенных народов, таких как Чакма, Шак, Куми, Мру, Лашаи, Трипури, Танчангья и др. До раздела Индии только $1.5 \%$ населения были мусульманами, подавляюее большинство коренных народов исповедовало буддизм и индуизм. Исторически эта территория находилась под властью индуистских правителей Типпера. Во второй половине 16 века Читтагонгский горный район был завоеван буддийским королевством Аракан (историческая область на северо-востоке Мьянмы).

В 1760 г. Британская Ост-Индская компания смогла завоевать Бенгалию, после чего северовосточные области оказались в сфере интересов колониальных властей. А с 1787 г. в результате военного поражения чакма район находился под фактической властью британской администрации при сохранении значительной политической автономии. Вмешательство в традиционные устои, традиции и обычаи местных племен не допускалось.

В 1900 г. колониальные власти издали Акт о Читтагонгском горном районе, согласно которому было ограничено переселение в эту область некоренных народов и запрещена любая передача земли, принадлежащей местным жителям, также закреплялось их право на автономию и политическое саморегулирование. Правительственное постановление 1935 г. подтвердило положения Акта 1900 г. и обозначила особый статус Читтагонгского горного района.

\section{Причины и волны миграции}

Раздел Британской Индии стал одним из ключевых событий, определивших историческую судьбу народа чакма. Жители Читтагонгского горного района до последнего момента были убеждены, что их область войдет в состав Индии. Такая уверенность основывалась на том, что народы Читтагонгского горного района с языковой и культурной точки зрения были ближе к коренным народам северо-восточных штатов Индии, чем мусульманам-бенгальцам. Вопреки всем ожиданиям по решению Бенгальской пограничной комиссии Читтагонгский горный район отошел Пакистану [6].

Проведение границы без учета этнических реалий региона дестабилизировало систему межобщинных отношений, стало причиной нарастания конфликтогенного потенциала, в конечном итоге привело к активизации массовых миграции чакма из региона. Дискриминационная политика по отношению к национальным меньшинствам, проводимая Пакистаном, привела к еще большей поляризации межэтнических отношений. В 50-60-х гг. правительство Пакистана приступило к активному хозяйственному освоению северо-восточных районов страны, сопровождавшееся массовым переселением бенгальцев-мусульман, тем самым фактически упразднив особый статус Читтагонгсого горного района. Отторжение у местного населения земли в пользу бенгальцев сопровождалось насилием и привело к первой волне миграции беженцев чакма на территорию Индии.

Вторая волна миграции стала следствием строительства гидроэлектростанции в Каптае, начатое руководством страны в 1960 г. Созданное в ходе реализации этого проекта водохранилище затопило район проживания чакма, под водой оказались 18 тыс. домов и обширные сельскохозяйственные угодья. В результате почти 100 тыс. чакма оказались без крыши над головой и средств к существованию [6]. Правительство практически не оказывало никакой помощи пострадавшим. 
В 1971 г. в результате гражданской войны и распада Пакистана было образовано независимое государство Бангладеш. Новое руководство продолжило дискриминационную политику по отношению к национальным меньшинствам. Согласно принятой конституции, подчеркивалось, что гражданами страны могли быть исключительно бенгальцы. Построение моноэтнического и монокультурного государства на основе бенгальской идентичности сопровождалось насильственной аккультурацией малых народов. Несмотря на широко тиражируемое мнение о гомогенном характере этнокультурного ландшафта Бангладеш, в стране насчитывается не менее 45 этносов, из которых Чакма является самым многочисленным [7].

Отказ правительства признавать национальные меньшинства стал причиной эскалации напряженности в Читтагонгском горном районе и радикализации протестного движения. Попытка правительства решить вопрос силовым методом, привела к вооруженному конфликту между бангладешской армией и повстанческими группировкам. Спасаясь от гражданской войны, тысячи беженцев чакма третьей волны искали убежище на территории Индии. Один из самых масштабных притоков мигрантов произошел в 1986 г. с прибытием 51 тыс. чакма в Индию.

\section{Последствия миграции и попытки урегулирования}

В 1994 г. согласно плану о репатриации в двустороннем соглашении правительств Индии и Бангладеш, 25 тыс. мигрантов вернулось на родину. В 1997 состоялась встреча правительственной делегации Бангладеш и Шанти Бахини (вооруженная группировка народа чакма) в результате которой было подписано мирное соглашение между сторонами, а часть беженцев репатриированы. В связи с этими событиями Индию нередко обвиняют в принуждении мигрантов к репатриации. Около 200 тыс. чакма из разных волн миграции до сих пор проживают в северо-восточных штатах Индии [8].

Большое число беженцев переселили в район штата Аруначал-Прадеш. В 1972 г. Индира Ганди и премьер-министр Бангладеш Муджибур Рахман заключили двустороннее соглашение, по которому Индия взяла на себя ответственность за мигрантов, прибывших в страну до 25 марта 1971 г. и обязалась предоставить им индийское гражданство [6].

Решение о предоставлении гражданских прав встретило отпор у местных властей. И даже в настоящее время беженцам чакма, проживающим в штате Аруначал-Прадеш на протяжении более 50 лет, так и не удалось получить официальный статус, руководство штата последовательно отказывает им в признании. На сегодняшний день чакма из Аруначал-Прадеш имеют статус лиц без гражданства.

Арунчал-Прадеш - относительно небольшой штат, для структуры народонаселения которого размещение тысяч беженцев чакма имеет решающее значение. Начиная с самых первых волн миграции чакма, местные власти настаивали на их депортации. С начала 1990-х годов община чакма усилила свою борьбу за гражданские права, обвинив правительство штата в нарушениях прав человека. В январе 2004 г. чакма добились включения 1,497 чел. в списки избирателей, что стало значимым шагом в борьбе за признание [9].

Местные жители воспринимают чакма как потенциальную угрозу племенной культуре и традициям, а местные власти выражают опасения, что признание чакма изменит демографию штата. Они опасаются, что 65 тыс. беженцев чакма в будущем могут стать доминирующей политической силой, в результате чего вопрос о депортации будет закрыт автоматически. Еще больше местные жители обеспокоены постепенной передачей земли беженцам. Кроме того, беженцев также обвиняют в посягательстве на земли лесных заповедников [9]. Так, в феврале 2019 г. в обществе активно обсуждалась новость о том, что около 400 чел. из общины чакма разбили лагерь в заповедном лесу. Для организации поселения, чакма срубили тиковые деревья общей стоимостью в 20 млн. рупий. [10] Серьезную обеспокоенность властей штата вызывают подозрения в связи беженцев чакма с подпольными экстремистами, действующими в Трипуре [9].

Отказ местных властей штата предоставить беженцам официальный статус вынудил Верховный суд вмешаться в ситуацию. В 1995 г. Суд постановил правительству Арунчал-Прадеш провести регистрацию чакма в записях о гражданстве. Местные власти проигнорировали его исполнение. В 2015 г. ситуация повторилась - Верховный суд обязал предоставить гражданство беженцам чакма, которые мигрировали из Бангладеш до 1971 г. Однако местные власти до сих пор не предприняли попыток к исполнению этого постановления [8].

В 2016 г. была принята поправка к Закону о гражданстве, согласно которой предполагалось предоставить гражданство лицам, прибывшим в страну из Афганистана, Бангладеш и Пакистана, и принадлежащим к индуистам, сикхам, буддистам, джайнам, парсам или христианам. Эта поправка встретила широкую критику со стороны северо-восточных штатов [11]. 
В 2017 г. Ассамблея штата Аруначал-Прадеш приняла резолюцию, в которой содержалась просьба к центральным властям учитывать права коренного населения при рассмотрении вопроса о предоставлении гражданства беженцам чакма [12]. Общинные лидеры чакма увидели в данной резолюции предлог для отказа местных властей решить проблему и подвергли критике главного министра [12].

В дополнение к политической стороне вопроса, гуманитарные последствия для беженцев были удручающими. Из-за отсутствия официального статуса чакма, лишены доступа к таким базовым правам, как образование, здравоохранение, свобода перемещения. Общинных школ очень мало, и большинство из них предоставляют только 4-5 классное образование, 55\% беженцев чакма неграмотны. Вероятно, можно утверждать, что среди всех групп беженцев, проживающих в Индии, ситуация с народом чакма вызывает наибольшие опасения [6].

\section{Заключение}

Таким образом, проблема чакма является одним из ярких примеров разрушительного наследия колониальной политики. События, которые произошли более полувека назад, находят свое отражение в политических и социокультурных проблемах штата Арунчал-Прадеш в наши дни. Последствия мирополитических изменений или региональных событий, таких как деколонизация, войны, политические гонения, этноконфессиональные конфликты, природные и техногенные катастрофы или социально-экономические проблемы - вот ряд факторов способствующих возрастанию числа беженцев в мире. Беженцы чакма столкнулись с рядом таких факторов.

Являясь следствием нестабильности, массовые вынужденные перемещения в свою очередь сами могут стать причиной напряженностей, которые зачастую перерастают в национальные, региональные и даже международные конфликты. Поток беженцев может вызвать острый социально-политический кризис в стране пребывания, привести к дестабилизации системы межэтнических и межконфессиональных отношений, ухудшить экономические условия жизни местного населения. Ряд этих закономерностей можно наблюдать в ходе развития вопроса об урегулировании проблемы чакма, который существенно затронул политическую и социальную стабильность СевероВосточной части Индии, в большей степени штат Арунчал-Прадеш, что только усугубляется сообщениями об экстремизме беженцев чакма.

Разобщенность центральных властей Индии и местных властей штата является прямым препятствием к мирному урегулированию. Стоит отметить, что Бангладеш перестал участвовать в урегулировании после соглашения с Индирой Ганди, что так же негативно сказывается на положении беженцев. Более того, автор исследовал ряд документов Управления верховного комиссара ООН по делам беженцев (УВКБ), в которых не уделяется должного внимания решению проблемы бедственного положения чакма. В условиях глобализации, интенсификации и интернационализации международной жизни, проблемы беженцев давно вышли за пределы локальных вопросов и приобрели трансграничный характер. На примере чакма видно, что решение вопросов беженства сегодня невозможно исключительно на уровне местных или национальных властей, требуется региональное и международное взаимодействие.

\section{Литература}

1. UNHCR UNHCR STATISTICS. The World in Numbers [Электронный ресурс]. Режим доступа: http://popstats.unhcr.org/en/overview\#_ga=2.182524133.2139157402.15576976671299877512.1557697667 (дата обращения 20.05.2019)

2. UN Глобальные вопросы повестки дня. [Электронный ресурс]. Режим доступа: https://www.un.org/ru/sections/issues-depth/global-issues-overview/ (дата обращения 10.05.2019)

3. UN Определения. [Электронный ресурс]. Режим доступа: https://refugeesmigrants.un.org/ru/definitions (дата обращения 10.05.2019)

4. Доклад Верховного комиссара Организации Объединенных Наций по делам беженцев За период с 1 июля 2016 года по 30 июня 2017 года. (A/72/12) [Электронный ресурс]. Режим доступа: https://www.refworld.org/cgi-bin/texis/vtx/rwmain/opendocpdf.pdf?reldoc=y\&docid=59c8d9774 (дата обращения 17.05.2019)

5. UNHCR Populations of Concern to UNHCR. [Электронный ресурс]. Режим доступа: http://reporting.unhcr.org/sites/default/files/gr2017/pdf/01c_PoC.pdf (дата обращения 22.05.2019)

6. Chakma Jyoti Bikash. The great exodus of the Chakmas and its aftermath: an overview. // International Seminar on Society, Polity and Economy of the Chakmas on 12-13 December 2013 - P. 1.

7. Chowdhury Raqib: Being and Seeing Chakma. - 2015. [Электронный ресурс]. Режим доступа: https://www.researchgate.net/publication/318094191_Being_and_Seeing_Chakma P.41 (дата обращения 20.05.2019) 
8. The Hindu. Who are Chakmas? Sep. 14, 2017 [Электронный ресурс]. Режим доступа: https://www.thehindu.com/news/national/who-are-chakmas/article19682129.ece (Дата обращения 14.05.2019)

9. Institute of peace and conflict studies. Arunachal Pradesh: The Chakma-Hajong Refugee Crisis - 2005. [Электронный ресурс]. Режим доступа: http://www.ipcs.org/focusthemsel.php?articleNo=1687 (Дата обращения 22.05.2019)

10. Timesofindia. 400 Chakmas escape to Tripura from Arunachal Pradesh - 2019 . [Электронный ресурс]. Pежим доступа: https://timesofindia.indiatimes.com/city/agartala/400-chakmas-escape-to-tripura-fromarunachal-pradesh/articleshow/67813863.cms (Дата обращения 21.05.2019)

11. The Hindu. What is the Citizenship (Amendment) Bill, 2016? - 2018. [Электронный ресурс]. Режим доступа: https://www.thehindu.com/news/national/other-states/what-is-the-citizenship-amendment-bill2016/article23999348.ece (Дата обращения 14.05.2019)

12. Hindustantimes. Arunachal assembly resolution on citizenship to Chakmas, Hajongs kicks up fresh row 2017. [Электронный ресурс]. Режим доступа: https://www.hindustantimes.com/india-news/arunachalassembly-resolution-on-citizenship-to-chakmas-hajongs-kicks-up-fresh-row/story1kom96LXBuC0BM80LeNy7L.html (Дата обращения 18.05.2019)

Kontcova Elizaveta Andreevna, postgraduate student, Saint-Petersburg State University (7-9, Universitetskaya Emb., St. Petersburg, 199034, Russian Federation). E-mail: elizabethkontsova@gmail.com

\title{
CHAKMA REFUGEES: PROBLEMS AND PROSPECTS
}

\section{Abstract}

In order to achieve sustainable development world society should pay attention to a single refugee case and try to find solutions to meet their needs, thus article considers Chakma refugees' problems and prospects to their resolutions. First part of the article studies history of Chakma people. Second part reviews main reasons of mass forced migration. Third part of the article is to consider attempts and current issues of settlement for Chakma refugees. Keywords: Chakma, refugee, forced migration, Southern Asia, regional security, Convention on the status of refugees, political consequences, breeding people, political autonomy.

\section{РАЗГРАНИЧЕНИЕ ПОНЯТИЙ «ЭТНОС» И «НАЦИЯ» В УСЛОВИЯХ НАЦИОНАЛЬНО-ТЕРРИТОРИАЛЬНОГО УСТРОЙСТВА РФ}

\author{
Рамазанова аспирант, Северо-Западный институт управления Российской академии \\ Патимат народного хозяйства и государственной службы при Президенте РФ \\ Рамазановна (199178, Россия, г. Санкт-Петербург, Средний пр. В.0., 57/43). \\ E-mail: pati-agent@mail.ru
}

\section{Аннотация}

Статья посвящена актуальной в настоящее время проблеме межэтнических и межнациональных отношений между различными социальными группами, и перспективы развития в России благоприятной ситуации в вопросах этнического взаимодействия. В статье рассматривается терминология таких понятий, как «этнос», «нация», «народ», изучается вопрос поэтапного развития одного понятия из другого и современного применения этих терминов в настоящее время. Особое внимание было уделено такому понятию, как «нация» в его негативном ключе и его воздействию на этнически группы внутри государств. В заключении раскрываются перспективы построения в России полиэтнического народа, объединенного на основании общности таких факторов, как исторический путь, ценности и идеи.

Ключевые слова: этнос, нация, этническая группа, национально-территориальное устройство, Российская Федерация, народ, социальные группы, полиэтнический народ, этническое взаимодейстьвие.

Актуальность темы исследования заключается в рассмотрении понятий «этнос» и «нация» и их взаимосвязи с национально-территориальным устройством Российской Федерации.

Как правило, мы используем такие понятия, как «нация», «этнос» или «народ» зачастую в одинаковом ключе, определяя их в качестве синонимов. Это вполне допустимо, однако с обязательным учетом того, что при более глубоком изучении между каждым из них в частности появляется разница, которая заставляет по-особенному взглянуть на данную терминологию и ее роль в развитии социологии и политологии.

Само определение термина «этнос» ранее традиционно использовалось применимо к людям с общим происхождением, в античную эпоху так именовали простые сообщества людей. Значительно позже термином «этнос» были наделены варварские племена.

При написании статьи автором были исследованы труды отечественных и зарубежных учёных, это в частности: А.А. Ашхамахова, А.А. Дадашев, А.Г. Дугин, а также А.Б. Паскачев, Ю.И. Семенов 